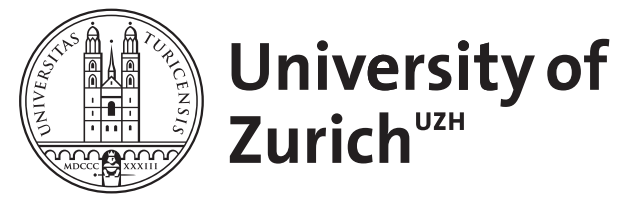

Zurich Open Repository and Archive

University of Zurich

University Library

Strickhofstrasse 39

CH-8057 Zurich

www.zora.uzh.ch

Year: 2004

Intraindividual variability, change, and aging: conceptual and analytical issues

Martin, Mike ; Hofer, S M

DOI: https://doi.org/10.1159/000074382

Posted at the Zurich Open Repository and Archive, University of Zurich ZORA URL: https://doi.org/10.5167/uzh-2205

Journal Article

Published Version

Originally published at:

Martin, Mike; Hofer, S M (2004). Intraindividual variability, change, and aging: conceptual and analytical issues. Gerontology, 50(1):7-11.

DOI: https://doi.org/10.1159/000074382 


\title{
Intraindividual Variability, Change, and Aging: Conceptual and Analytical Issues
}

\author{
Mike Martina Scott M. Hofer ${ }^{b}$ \\ aDepartment of Gerontopsychology, Institute of Psychology, Zurich, Switzerland; bPennsylvania State University, \\ University Park, Pa., USA
}

\author{
Key Words \\ Cognitive aging · Intraindividual variability • \\ Longitudinal studies - Theories of aging · Adaptation
}

\begin{abstract}
Background: Developmental researchers use a variety of research designs to examine aging-related changes. Most longitudinal studies of aging are based on research designs that feature successive, widely spaced, assessments to estimate changes in cognitive performance. Such designs assume that short-term variations in cognitive performance are small relative to long-term changes or have modeled such phenomena as nuisance parameters. Objective: There is now sufficient empirical evidence to establish intraindividual cognitive variability as a systematic source of individual differences and of important predictive value for aging-relevant outcomes. Methods: After an overview of types of change, potential underlying processes, and adequate analytic designs, we discuss consequences for lifespan aging research. Results: We emphasize that interpretations of both cross-sectional and longitudinal results need to consider
\end{abstract}

Paper presented at the International Workshop on Methods Examining Variability in Lifespan Aging Research, Heidelberg, Germany, February 2002.

\section{KARGER}

Fax +41613061234

E-Mail karger@karger.ch

www.karger.com
(C) 2004 S. Karger AG, Basel

0304-324X/04/0501-0007\$21.00/0

Accessible online at:

www. karger.com/ger and specify theoretical assumptions about short-term and long-term changes. Conclusions: Above and beyond the analysis of long-term mean changes, shortterm changes are an important aspect of aging-related change, and their analysis may help to explain psychological processes of adaptation.

Copyright $@ 2004$ S. Karger AG, Basel

Research on aging examines ordered changes that can be meaningfully related to chronological age and agegraded periods of development across the lifespan. Theoretical positions differ widely with respect to the explanatory domain (e.g., emotions, intellectual performance, social behavior, or attitudes), the parts of the lifespan in focus (e.g., infants, children, adolescence, adulthood, or old age), the outcome variable in focus (e.g., well-being, health, intelligence, or professional success), the explanatory constructs (e.g., knowledge, inhibition, speed of processing), the length of time for developmental predictions (e.g., early childhood to old age vs. middle adulthood to old age), and the specificity of predictions. Overall, most theoretical positions and empirical findings speak to the question of long-term changes, i.e., how particular explanatory developmental parameters earlier in life influence the developmental outcome parameters such as wellbeing, health or intelligence later in life [1]. Hence, psychological aging research is generally focussing on the

Mike Martin

Institute of Psychology, Department of Gerontopsychology

Schaffhauserstrasse 15

$\mathrm{CH}-8006$ Zürich (Switzerland)

Tel. +41 163534 30, Fax +41 163534 21, E-Mail m.martin@psychologie.unizh.ch 
detection of reliable age-related long-term change in psychological processes such as thinking, learning, reasoning, emotions, personality, motivation, or, generally, behavior.

Most longitudinal studies of aging are based on research designs that feature successive, widely-spaced, assessments to estimate changes in cognitive performance. Such designs assume that short-term variations in cognitive performance are small relative to long-term changes. Indeed, if short-term temporal variability is moderate to high, then single assessments would likely produce imprecise estimates of an individual's characteristic level of cognitive functioning and has implications for estimates of individual change. Although the focus on long-term change has not emphasized short-term variation or has approached modeling such phenomena as nuisance parameters, short-term intraindividual variability has long been considered an interesting outcome in itself. There is now sufficient empirical evidence that establishes intraindividual cognitive variability as a substantial source of systematic performance variability between people, especially in older adults [2-5].

Of course, not all of the short-term intraindividual variability contains theoretically or practically meaningful information (see Nesselroade's commentary). In many cases, however, short-term intraindividual variability or change might contain meaningful information about psychological processes of interest. In fact, there may be many different manifestations of short-term change and several possible theoretical interpretations. For example, intraindividual short-term variability may be an early indicator of deficits [6] or later-onset declines [7]. With respect to the differentiation-dedifferentiation [8] or the 'common cause' hypothesis [9], intraindividual shortterm variability might be indicative of the structure of aging-related changes. Intraindividual short-term variability could also indicate adaptive behavior to cope with a stressful event or the limitations that go along with physical ailments. As an example, an increase in short-term intraindividual variability in extreme old age is not necessarily maladaptive. To maintain low levels of variability in developmental outcomes such as well-being or health requires a high level of regulatory effort. If, however, individual energy levels are low [e.g., 10], it might be maladaptive to invest energy in the stability of a particular outcome variable. Given limited resources, such efforts might affect functioning in other life domains, e.g., social activities. Instead, setting wider margins between a maximum and minimum value for the variability of a particular outcome variable may reduce the effort required to balance functioning in both domains. As a consequence, within- and across-domain short-term intraindividual variability might increase.

\section{Theoretical Basis for Short-Term Intraindividual Variability}

Theories of development that attempt to explain agerelated changes should consider specifications of which short- and long-term intraindividual change relations are theory-relevant and to which time scales predictions apply. In addition to specifying that there should be agerelated changes in both explanatory concepts (e.g., in speed) and aging-related outcomes (e.g., fluid intelligence), it is possible to specify what longitudinal shortand long-term relations are to be expected or if the theory even applies to particular time frames of change. As a consequence, to test the 'common cause' hypothesis, one may ask if independent dimensions of intellectual functioning are more highly related at extreme old ages compared to middle age, i.e., a long-term prediction, and/or if within persons of different ages there is an increase in the covariance of short-term fluctuations in performance in independent dimensions of intellectual functioning, i.e., a short-term prediction. In this context, hypotheses about within-person changes need to be formulated and tested separately from hypotheses about population mean changes [e.g., 11].

So far, there is little research on systematic intraindividual aging-related short-term variability, i.e., on the interaction between short-term intraindividual variability of explanatory parameters and intraindividual changes in other short-term developmental outcome parameters [e.g., 2-5]. There is also very little research on the predictive value of short-term intraindividual variability on later short-term variability, long-term changes, or long-term outcomes [13]. With adequate research designs, the examination of short-term intraindividual variability offers new possibilities for developmental research in many domains of psychological functioning. Results from these study designs may help to answer questions about the generality vs. specificity of intraindividual variability and about age-related differences in the range of observable intraindividual short-term variability. In the long run, these designs might add to the specificity of theories and predictions and support the development of tools allowing the early detection of problematic development. 


\section{Conceptual Basis for Short-Term Intraindividual Variability}

Conceptually, the aging of an individual can be considered the development of a dynamic system of functional and goal processes within the context of environmental and developmental tasks. The processes within the system can be described by four related concepts: The concept of homeostasis emphasizes steady state and optimal set points. Allostasis refers to the maintenance of stability through change. It emphasizes optimal operating ranges of physiological systems given cumulative effects of stress on health and longevity. The concept of allostatic load assumes that stability through change represents the cumulative, multi-system view of physiological toll that may be exacted on the body through attempts at adaptation. Rheostasis refers to the regulated, controlled change in set points. More specifically, to examine covariations between short-term changes, a number of processes potentially causing intraindividual changes over time can be assumed to occur: (a) calibrating processes to match behavioral responses to environmental demands [14]; (b) compensating processes to stabilize a particular goal function such as well-being [15]; (c) reactive processes after reaching a critical threshold value in one or more relevant domains [16]; (d) optimization processes to coordinate parallel processes aiming at stabilizing different goal functions or hierarchies of goal functions [17]; (e) processes of fitting strategies with environmental demand, e.g., when practice effects lead to frequent use of a single strategy [18]; (f) anticipatory processes to prepare reactions to potential environmental changes [19]; (g) search processes trying out different ways to adapt to changing environmental conditions [20], and (h) adaptive processes after resetting minimum and/or maximum threshold values for one or more goal functions due to lack of energy to compensate the impact of events or stress [21].

\section{Research Designs to Examine Short-Term Intraindividual Variability}

Age-related increases in intraindividual variability have often been ascribed to the lack of instrument reliability (and validity) that can only be overcome by the power of large samples. One other way of approaching shortterm intraindividual variability is to control non-informative short-term fluctuations and to test for additional, statistically reliable short-term intraindividual variability that is theoretically and practically meaningful. The research designs in combination with the statistical methods described in the papers of this special section may thus take into account interindividual differences in intraindividual change within a number of developmental domains. More importantly, these approaches permit formulation and empirical tests of hypotheses about the processes influencing development and aging at the individual level of analysis.

One may, for example, assume that lower levels of intraindividual variability (i.e., stability) in important goal functions such as health, well-being or information processing performance, require (compensatory) energy [e.g., 10]. This assumption can only be examined with a focus on short-term intraindividual variability. From this perspective, lower levels of intraindividual short-term variability are adaptive when tasks require high precision, when persons are close to their maximum performance level (variability would mean a decrease), when the behavior shown is efficient, when sufficient resources are available to compensate for distractions, and when the person tries to maximize a single process or goal function (e.g., intellectual functioning). In the same case, higher levels of intraindividual short-term variability are adaptive when the optimal behavior is unknown and it is preferable to try the effectiveness of the available behaviors, when persons are close to the minimum of their performance level, when low levels of energy are available to compensate distractions, and when the focus is on the optimization of two or more processes or goal functions (e.g., intellectual functioning and social activities). Across the lifespan, the precision required by tasks encountered, the availability of effective strategies, the level of competence and energy, and the focus on one or more goal functions probably changes. Only if changes in short-term intraindividual variability are included in building or reformulating lifespan developmental theories do we have the chance to receive a more complete picture of the adaptive capacities of persons at different ages.

\section{Sampling Time}

The study of intraindividual variation and covariation is not new. The well-known short form of Cattell's [22] data box provides an analytical framework for sampling across time, variables, and participants, the long form of the data box included other important aspects for understanding individual development by examining the environmental background and phase of the background, state 
of the organism, and other static and time-varying aspects of the context and participant. Given the interest in intraindividual variation, decisions regarding the sampling of time within individuals requires attention. Traditionally, the importance of sampling time has not been emphasized in developmental and aging research. We do expect, however, that change over time can follow many forms and these are likely to be different for combinations of different people, outcomes, and age periods. In terms of aging research, change can be gradual for periods of midlife, abrupt and nonlinear if related to acute illness, and may rebound to the previous level and so be described as interrupted plateaus or transitional in nature [23]. If our focus is on individual-level processes, research designs must be sensitive to all types of change in order to identify patterns and magnitudes of change within individuals. Given both systematic and stochastic sources of fluctuation in individual characteristics over short periods of time, such designs must also be sensitive to intraindividual variation $[24,25]$.

The sampling of time will influence analysis and interpretation of intraindividual variability and short-term change. Indeed, we might expect that different intervals will yield different patterns of variability and result from different influences on the 'system' or individual. For example, we might consider sampling moment to moment (attentional lapses); within-test (fatigue, practice); within-session (fatigue, order effects, motivation); within day (time of day effects); across days or weeks (environmental perturbations, physical health, practice); months or years (characteristic change trajectory). There is an increasing interest and development of methods for the evaluation of temporal dynamics of these types [26, 27].

Temporal sampling designs can take many forms. One such design, the measurement burst design [28, 29], utilizes intensive measurements over a short period in time and follow-up with further measurement burst sessions after longer intervals and permits a window on individual-level characteristics as well as long-term change. Obtaining multiple, closely spaced assessments at each wave allows local temporal smoothing of data for each individual by averaging across multiple assessments. The addition of multiple indicators at each assessment permits further improvements in the modeling of random error components in models that incorporate true change. By improving measurement precision through multiple assessments or multiple indicators, such designs will increase statistical power to detect cognitive change at both the individual and aggregate sample levels and permit greater understanding of intraindividual processes within and across different time intervals. Indeed, measurement burst designs incorporating multiple indicators would permit an optimal opportunity for evaluating systematic short-term fluctuation and change. A further consideration is the context in which measurements are obtained. Most temporal sampling designs are performed under random contextual backgrounds, but individual variation in performance can be evaluated against defined contexts as well - more akin to experimental paradigms (e.g., levels of stress, dual-processing tasks).

\section{Special Section on Intraindividual Variability}

The set of manuscripts in this special section is based on presentations given at a conference on intraindividual variability held at The German Centre for Research on Ageing at The University of Heidelberg, February 2002. They represent a broad array of research that treats intraindividual variability and short-term change as important characteristics of an aging organism. The papers discuss issues of theory, domain specificity of changes, and stateof-the-art methodology. We see this renewed interest in intraindividual variation and short-term change as an important contribution to the study of aging. Intraindividual variability has often been dealt with as a confound or nuisance factor in single-measurement designs and repeated single-measurement designs. New applications of measuring intensive longitudinal designs, however, permit analysis of aggregate or characteristic level of functioning of the individual as well as features of variation and covariation within individuals. A commentary by John Nesselroade, a strong and consistent voice on the importance of studying intraindividual variation and covariation, concludes this special section. 


\section{References}

1 Martin P, Martin M: Proximal and distal influences on development: Introducing the model of developmental adaptation. Dev Rev 2002;22:78-96.

2 Hultsch D, Hertzog C, Small BJ, McDonaldMiszczak L, Dixon RA: Short-term longitudinal change in cognitive performance in later life. Psychol Aging 1992; 7:571-584.

3 Li S, Aggen SH, Nesselroade JR, Baltes PB Short-term fluctuations in elderly people's sensorimotor functioning predict text and spatial memory performance: The MacArthur Successful Aging Studies. Gerontology 2001;47: 100-116.

4 Nesselroade JR: Intraindividual variability in development within and between individuals. Eur Psychol 2001;6:187-193.

5 Strauss E, MacDonald SW, Hunter M, Moll A, Hultsch DF: Intraindividual variability in cognitive performance in three groups of older adults: Cross-domain links to physical status and self-perceived affect and beliefs. J Int Neuropsychol Soc 2002;8:893-906.

6 Schaie KW: The impact of longitudinal studies on understanding development from young adulthood to old age. Int J Behav Dev 2000;24: 257-266.

7 Rowe JW, Kahn RL: Successful aging. Gerontologist 1997;37:433-440.

8 Li SC: Connecting the many levels and facets of cognitive aging. Curr Direct Psychol Sci 2002; 11:38-43.

9 Christensen H, Mackinnon AJ, Korten A: The 'common cause hypothesis' of cognitive aging: Evidence for not only a common factor but also specific associations of age with vision and grip strength in a cross-sectional analysis. Psychol Aging 2001;16:588-599.

10 Fairclough SH: Mental effort regulation and the functional impairment of the driver; in Hancock PA, Desmond PA (eds): Stress, Workload, and Fatigue: Human Factors in Transportation. Mahwah, Erlbaum, 2001, pp 479-502.
11 Zimprich D, Martin M: Can longitudinal changes in processing speed explain longitudinal age changes in fluid intelligence? Psychol Aging 2002;17:690-695.

12 Kim JE, Nesselroade JR: Relationships among social support, self-concept, and wellbeing of older adults: A study of process using dynamic factor models. Int J Behav Dev 2003;27:49_ 63.

13 Eizenman DR, Nesselroade JR, Featherman DL, Rowe JW: Intraindividual variability in perceived control in a older sample: The MacArthur successful aging studies. Psychol Aging 1997; 12:489-502.

14 Ceci SJ, Baker JG, Bronfenbrenner U: Prospective remembering, temporal calibration, and context; in Gruneberg MM, Morris PE (eds): Practical Aspects of Memory: Current Research and Issues. 1. Memory in Everyday Life. Oxford, Wiley, 1988, pp 360-365.

15 Staudinger U, Freund A, Linden M: Self, personality, and life regulation: Facets of psychological resilience in old age; in Baltes PB, Mayer KU (eds): The Berlin Aging Study: Aging from 70 to 100 . New York, Cambridge University Press, 1999, pp 302-328.

16 Perlesz A, Kinsella G, Crowe S: Impact of traumatic brain injury on the family: A critical review. Rehabil Psychol 1999;44:6-35.

17 Sherrod LR: Using the selection, optimization and compensation model to take us one step further in developmental research. Hum Dev 2001;44:51-54.

18 West RL: Compensatory strategies for ageassociated memory impairment; in Baddeley AD, Wilson BA (eds): Handbook of Memory Disorders. Oxford, Wiley, 1995, pp 481-500.

19 Mailles S, Marine C, Cellier J: Anticipatory behavior in a simulated bus traffic control task; in De Keyser V, d'Ydewalle G (eds): Time and the Dynamic Control of Behavior. Kirkland, Hogrefe \& Huber, 1998, pp 303-317.

20 Luszcz M, Hinton M: Domain- and task-specific beliefs about memory in adulthood: A microgenetic approach. Aust Psychol 1995;47: $54-59$.
21 Martin P, Long MV, Poon LW: Age changes and differences in personality traits and states of the old and very old. J Gerontol 2002; 57B:P144-P152.

22 Cattell RB: The data box: Its ordering of total resources in terms of possible relational systems; in Nesselroade JR, Cattell RB (eds): Handbook of Multivariate Experimental Psychology, ed 2. Perspectives on Individual Differences. New York, Plenum Press, 1988, pp 69-130.

23 Birren JE, Schroots JF: History, concepts, and theory in the psychology of aging; in Birren JE Schaie KW (eds): Handbook of the Psychology of Aging, ed 4. San Diego, Academic Press, 1996, pp 3-23.

24 Baltes PB, Nesselroade JR: The developmenta analysis of individual differences on multiple measures; in Nesselroade JR, Reese HW (eds) Life-span developmental psychology: Methodological issues. Oxford, Academic Press, 1973.

25 Nesselroade JR: The warp and the woof of the developmental fabric; in Downs RM, Liben LS (eds): Visions of aesthetics, the environment \& development: The legacy of Joachim F. Wohlwill. Hillsdale, Lawrence Erlbaum, 1991, pp 213-240.

26 Boker SM, Nesselroade JR: A method for modeling the intrinsic dynamics of intraindividual variability: Recovering the parameters of simulated oscillators in multi-wave panel data. Multivar Behav Res 2002;37:127-160.

27 Molenaar PC: A dynamic factor model for the analysis of multivariate time series. Psychometrika 1985;50:181-202.

28 Nesselroade JR: The warp and the woof of the developmental fabric; in Downs RM, Liben LS (eds): Visions of Aesthetics, the Environment \& Development: The legacy of Joachim F. Wohlwill. Hillsdale, Lawrence Erlbaum, 1991, pp 213-240.

29 Nesselroade JR, Schmidt-McCollam KM: Putting the process in developmental processes. Int J Behav Dev 2000;24:295-300. 